doi:10.22306/atec.v6i1.71

\title{
ECO - FRIENDLY CUSTOMIZED GEOPOLYMER COMPOSITE
} MATERIALS

\author{
Lucia Knapčíková \\ Technical University of Košice, Faculty of Manufacturing Technologies with a seat in Prešov, Department of \\ Industrial Engineering and Informatics, Bayerova 1, 08001 Prešov, Slovak Republic, EU, \\ lucia.knapcikova@tuke.sk (corresponding author)
}

\section{Annamária Behúnová}

Technical University of Košice, Faculty of Manufacturing Technologies with a seat in Prešov, Department of Industrial Engineering and Informatics, Bayerova 1, 08001 Prešov, Slovak Republic, EU, annamaria.behunova@tuke.sk

\section{Marcel Behún}

Technical University of Košice, Faculty of Mining, Ecology, Process Control and Geotechnology, Institut of earth sources, Park Komenského 19, 04384 Košice, Slovak Republic, EU, marcel.behun@tuke.sk

\section{Patrik Kaščák}

Technical University of Košice, Faculty of Manufacturing Technologies with a seat in Prešov, Department of Industrial Engineering and Informatics, Bayerova 1, 08001 Prešov, Slovak Republic, EU, patrik.kascak@tuke.sk

Keywords: composites, geopolymers, waste, sustainable, customization

Abstract: One of the biggest problems facing humanity in recent years is the environmental pollution from industrial and municipal waste. Global efforts are being made to address these problems on a community-wide basis. Tyres are a major problem as the amount of waste increases in proportion to the demand for new cars. It is therefore essential to develop new environmentally and economically sound methods for recycling a waste tyre. From an economic point of view, the use of waste material is irreplaceable. The aim of the present paper is to utilize waste tyre fabrics as a filler which will use as a reinforcement in a geopolymer matrix. The geopolymer Baucis L 160 (cement and activator) and fabrics with a purity of 52\% were used for the manufacturing. The advantage of this material is its customized environmental, economic and social benefit for various areas of industries.

\section{Introduction}

The term geopolymers refers to inorganic polymeric materials which are prepared by the polycondensation reaction of basic aluminosilicate materials in a basic environment at normal temperature and pressure [1]. This reaction is referred to as geopolymerization.

Geopolymers belong to the group of mineral composite materials of unconventional composition, which are very similar to inorganic materials - zeolites.

Essentially, geopolymers are defined as calcium-free alkaline aluminosilicates most commonly prepared by alkaline activation of metakaolin with sodium or potassium hydroxide solution or water glass. The term geopolymer was first used in 1979, when this material was patented by prof. Joseph Davidovits, who described the geopolymer as a material [2].

Essentially, a geopolymer is an amorphous aluminosilicate material consisting of tetrahedral aluminium and siliceous units condensing at room temperature to form equilibrium structures in the presence of a monovalent alkali metal ion [3].
Such a material then exhibits very surprising properties, such as water solubility, non-flammability, and resistance to temperatures of about $1000^{\circ} \mathrm{C}$. their fire resistance [2,3].

The geopolymer polymer Parament ${ }^{\circledR}$, used to repair the Los Angeles airfield, and the geopolymer polymer composite carbon / Geopolymit $\AA$, used for fire-resistant lining of the aircraft cabin, have been developed for the construction industry [1,5].

Geopolymer and carbon fibre composites have been developed for aeronautics and Formula 1 cars. These composite materials are used in thermally stressed parts of the monopost, e.g. exhaust systems [4].

On the basis of customized users or applications, our research focuses on the manufacturing of geopolymer composites for major applications, sales volume, market share according to growth rate of each Global geopolymer customized applications (Figure 1) [2]. 


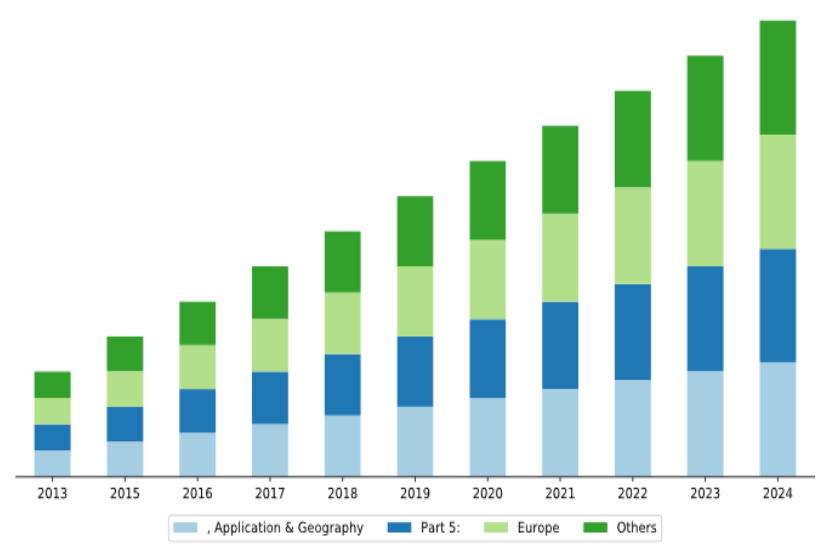

Figure 1 Global customized geopolymer applications $(y .2013-2024)[2]$

We presented following the key players who deal with worldwide geopolymers manufacturing and production [2]:

- $\quad$ PCI Augsburg GmbH (Basf),

- Schlumberger Limited,

- Wagner Global,

- ASK Chemicals,

- Milliken Infrastructure Solutions,

- INOMAT GmbH,

- W llne,

- Zeobond,

- Ecocem,

- Česke lupkové závody,

- Alchemy Geopolymer,

- Fengyuan Chemical.

The automotive industry is going through a difficult period due to customs, Brexit, economic conditions and very strict environmental legislation in Europe [3]. Nowadays, tyres are valuable source of raw material. It focuses on the emerging material from amounts collected or processes, for most materials, some percentage of the input material is lost during processing, due to removal of the rubber component, a metal fabric. Using waste tyres only for recycling itself makes no sense. Over 100 independent companies in all EU member States are recycling tyres across Europe [2,3]. There are many companies involved in collecting and processing information on the recovery or disposal of waste tyres in the world, and in Europe. One of the main organizations is ETRA (European Tyre Recycling Association), which collects information, processes, evaluates and informs the population about new possibilities for recovery and use of this commodity.

Some of the applications studied in Global Geopolymer report are:

- Automotive and Aerospace Industries,

- Building Materials,

- Transportation,

- Others.

\section{Characterization \\ of \\ material investigation- a work methodology \\ 2.1 Geopolymer as a matrix}

The geopolymer mixture compounds of cement (Table 1) and activator Baucis L 160 has a well-defined mixing ratio, which is indicated on the packages, but also in the product materials of the mixture. The ratio for this mixture is 5 parts by weight of cement to 4 parts by weight of activator, which can be seen in Figure 2 as a final homogenization of both components.

Table 1 Chemical composition of geopolymer cement Baucis L160 [4]

\begin{tabular}{|c|c|}
\hline Composition & Volume [\%] \\
\hline $\mathrm{Na}_{2} \mathrm{O}$ & 9,24 \\
\hline $\mathrm{MgO}$ & 2,12 \\
\hline $\mathrm{Al}_{2} \mathrm{O}_{3}$ & 24,03 \\
\hline $\mathrm{SiO}_{2}$ & 50,94 \\
\hline $\mathrm{SiO}_{3}$ & 0,44 \\
\hline $\mathrm{K}_{2} \mathrm{O}$ & 0,61 \\
\hline $\mathrm{CaO}$ & 10,08 \\
\hline $\mathrm{TiO}_{2}$ & 0,97 \\
\hline $\mathrm{FeO}$ & 0,85 \\
\hline$\Sigma$ & 99,28 \\
\hline
\end{tabular}

By homogenization of the Baucis L 160 cement and the activator was produced a geopolymer mixture (Figure 2), which was subsequently reinforced at a percentage of $1 \%$, $5 \%, 10 \%$ and $15 \%$ of the fabrics from waste tyres.

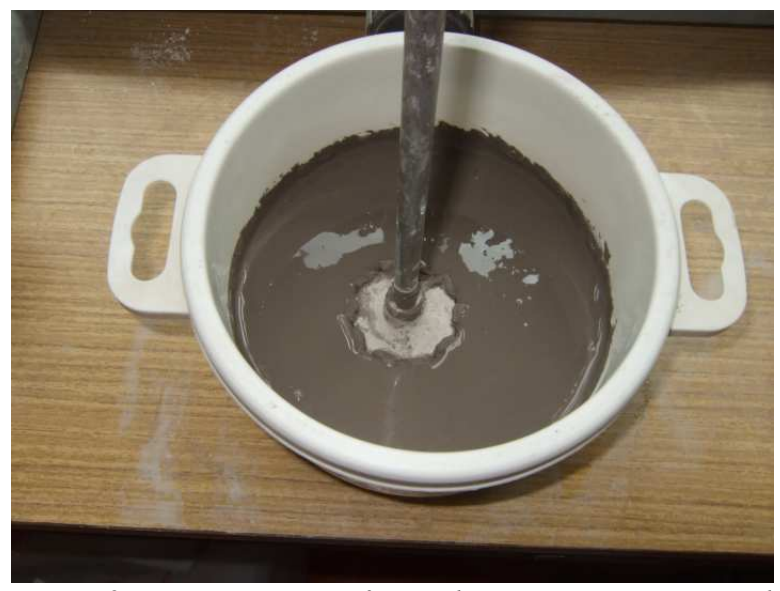

Figure 2 Homogenization of geopolymer composite material [authors own processing]

The production of one tonne of traditionally cements generates 0,55 tonnes of chemical $\mathrm{CO}_{2}$ and requires an additional 0,39 tonnes of $\mathrm{CO}_{2}$ in fuel emissions for baking and grinding, accounting for a total of 0,94 tonnes of

$\mathrm{CO}_{2}$. Other studies reported that the cement industry emitted in 2000 , on average, $0,87 \mathrm{~kg}$ of $\mathrm{CO}_{2}$ for every $\mathrm{kg}$ of cement produced. In general, the cement industry contributes about $7 \%$ of the total worldwide $\mathrm{CO}_{2}$ emissions [4]. This is the aim of our research and one of the most preferred advantage of used of geopolymer as a matrix by manufacturing of reinforced composites. 


\subsection{Fabrics from waste tyres as a filler}

Requirements for dismantling, reusing and recycling vehicles, and for their components, should be integrated into the design and manufacture of new vehicles. This Directive lays down measures and objectives where, firstly, the prevention of vehicle waste, as well as the reuse, recycling and other forms of recovery of End-Of-Life components and their components, are reduced to reduce waste disposal [2,3]. Last but not least, to improve environmental protection by all economic operators involved in the life cycle of vehicles and in particular operators directly involved in the processing of end-of-life vehicles. Figure 3 represents sample of fabrics from waste tyres after vibrating screens separation. The purity is $52 \%$.

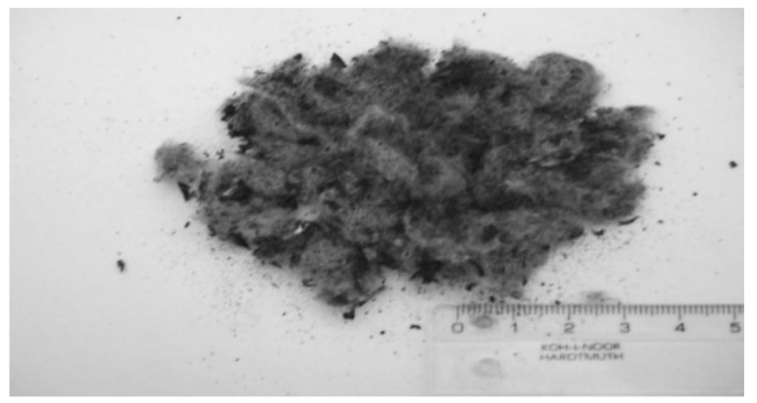

Figure 3 Fabrics from waste tyres after vibrating screens separation [authors own processing]

The main function of fibres in tyres is to provide the performance stability of the car through the required operating conditions. They represent special design and operating categories for a given car [3,5]. Ensuring high performance is one of many examples. The fabrics composition was mainly derived from the presence of cellulose and polyamide PA 6, also polyamide PA 6.6 for medium performance tyres. Polyesterterephthalate (PET), polyethyleneenaphthalate (PEN), and aramid are referred to as high performance tyre fibres [6]. They are also used to make commercial truck tyres [7]. The various national end-of-life vehicle measures should be harmonized to minimize the environmental impact of end-of-life vehicles, thus contributing to protecting, preserving and improving the quality of the environment and saving energy and, consequently, ensuring the smooth functioning of the internal market and avoid restricting competition in the EU community.

After mechanical testing/bending stress (Table 2, Figure 5) at maximal bending load we obtained results for 4 tested samples for each \% of filler were prepared 4 samples. Geopolymer composite material reinforced by $10 \%$ of waste tyre fabrics has value of $5,747 \mathrm{MPa}$ of bending stress by maximal bending force $\mathrm{F}_{\max } 2068,46 \mathrm{~N}$. For comparison, the $15 \%$ of filler has value of $4,000 \mathrm{MPa}$ by $1512,49 \mathrm{~N}$ of maximal bending load. This difference is due to homogenization of geopolymer composites material.

\section{Results and discussion}

After 28 days of geopolymer setting, we tested the geopolymer composite material and determined the strength characteristics, namely strain at break and elongation at break. Figure 4 shows a final sample of geopolymer composite material.

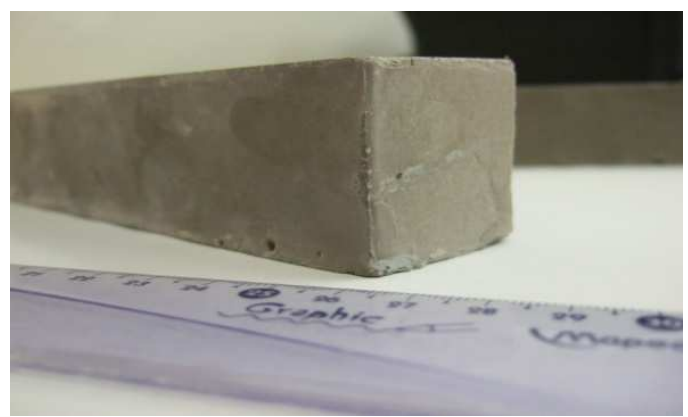

Figure 4 Geopolymer reinforced with fabrics from waste tyres [authors own processing]

Table 2 Bending Stress of tested geopolymer composites materials [authors own processing]

\begin{tabular}{|c|c|c|c|}
\hline & $\begin{array}{c}\mathbf{F}_{\max } \\
(\mathbf{N})\end{array}$ & $\begin{array}{c}\mathbf{A}_{\max } \\
(\mathbf{m m})\end{array}$ & $\begin{array}{l}\text { Bending stress at } \\
\text { maximal Bending } \\
\text { load (MPa) }\end{array}$ \\
\hline Red line & 1982.56 & 0.56 & 5.119 \\
\hline Brown line & 1906.58 & 0.89 & 4.745 \\
\hline Green line & 2068.46 & 0.73 & 5.747 \\
\hline Blue line & 1512.49 & 0.67 & 4.000 \\
\hline $\begin{array}{c}\text { Irregularity } \\
\text { coefficient }\end{array}$ & 13.15928 & 11.00214 & 14.89615 \\
\hline $\begin{array}{c}\text { Standard } \\
\text { deviation }\end{array}$ & 245.75260 & 0.07365 & 0.73031 \\
\hline Median & 1867.52 & 0.67 & 4.903 \\
\hline
\end{tabular}

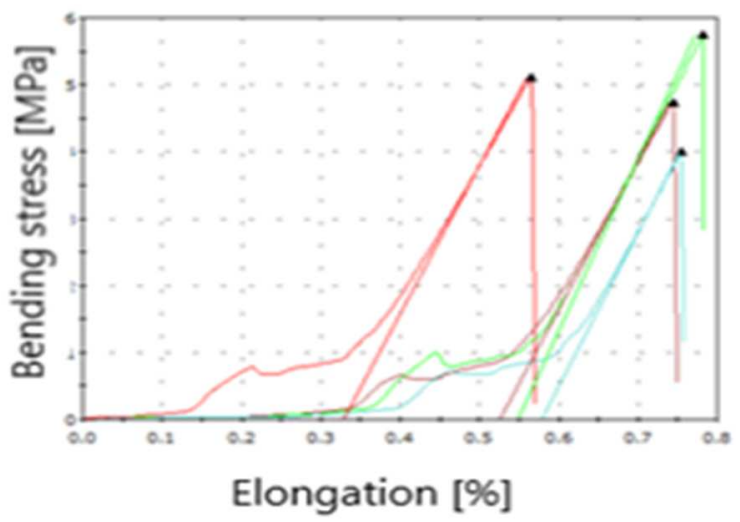

Figure 5 Dependence of elongation on bending stress [authors own processing]

Legend:

Red line- $1 \%$ fabrics from waste tyres,

Brown line- $5 \%$ fabrics from waste tyres,

Green line-10\% fabrics from waste tyres,

Blue line- $15 \%$ fabrics from waste tyres.

Based on the results we can say that the $10 \%$ proportion of waste textiles has the highest strength values. From a 
technological-processing point of view, it is important to say that in the production of geopolymer composite material we the possibility of reducing environmentally undesirable impacts on the environment, where we evaluated 3 key areas, which are:

- Production,

- Customization,

- $\quad$ Product disposal options.

During production it is necessary to analyse:

- Input raw materials,

- Energy,

- Human resource.

In customization, it is a complex view of:

- Output products - finished products,

- Customers,

Nowadays, waste is a substantial part of the whole product life cycle, where we focus on the possibility of:

- Landfilling,

- combustion,

- re-use materials,

- recycling.

\section{Conclusion}

Geopolymer composites materials have high resistance to aggressive environment of sulphate and chloride solutions. They are better resistant to acidic aggressive environments and are highly resistant to alternating freezing and thawing. The penetration of $\mathrm{Cl}^{-}$and $\mathrm{SO}_{4}{ }^{2-}$ ions into the mass of geopolymer materials is significantly lower than that of Portland cement masses. Geopolymers resist exposure to high temperatures up to $600-800{ }^{\circ} \mathrm{C}$, where residual strengths are greater than in Portland cements $[8,10]$.

The final properties of geopolymer composite materials are significantly influenced by the temperature and duration of geopolymerization, the starting material (chemical composition, particle size, $\mathrm{CaO}$ content), $\mathrm{Si}$ : $\mathrm{Al}$ ratio, activation solution concentration and composition, $\mathrm{pH}$, water content and solidification time $[9,10]$.

Geopolymer composite materials reinforced with fabrics from waste tyre have excellent mechanical strength due to a high degree of polycondensation, high durability (geopolymer concrete or mortar resists weathering without significant changes), unique heat-insulating properties, are easily recyclable, are resistant to heavy metals.

Based on the achieved results, we conclude that geopolymers can be considered as prospective materials meeting demanding technical as well as ecological requirements.

They are materials capable of competing technically with Portland cements and ecologically superior to them.

\section{References}

[1] ESWARAMOORTHI, P., ARUNKUMAR, G.E.: Fibres Study on Properties of Geopolymer concrete With Polypropylene, International Refereed Journal of Engineering and Science, Vol. 3, No. 2, pp. 60-75, 2014.

[2] Global Geopolymer Market Analysis 2013-2018 and Forecast 2019-2024, [online], Available: https://inforgrowth.com/report/1532220/geopolymermarket

[3] RAMUJEE, K., POTHARAJU, M.: Development of Mix Design for Low Calcium Based Geopolymer Concrete in Low, Medium and Higher Grades-Indian Scenario. Journal of Civil engineering and technology, Vol. 1, No. 1, pp. 15-25, 2013.

[4] ABDOLLAHNEJAD, Z., PACHECO-TORGAL, F, J.L.B.: Eco-concrete: One-part geopolymer mixes, Conference: TRF Senior Research Scholars Annual Conference II At: Khan Kaen, Thailand, 2013.

[5] KRISHNARAJA, A.R., SATHISHKUMAR, N.P., SATHISH KUMAR, T., DINESH KUMAR, P.: Mechanical Behaviour of Geopolymer Concrete under Ambient Curing, International Journal of Scientific Engineering and Technology, Vol. 3, No. 2, pp. 130132, 2014.

[6] KRISHNAN, L., KARTHIKEYAN, S., NATHIYA, S., SUGANYA, K.: Geopolymer Concrete an EcoFriendly Construction Material, International Journal of Research in Engineering and Technology, Vol. 3, Spec. No. 11, pp. 164-167, 2014.

[7] LLOYD, N.A., RANGAN, B.V.: Geopolymer Concrete with Fly Ash, International Conference on sustainable construction materials and technologies, 2010.

[8] REED, M., LOKUGE, W., KARUNASENA, W.: Fibre- Reinforced Geopolymer Concrete with Ambient Curing for In Situ Applications, Journal of Material Science, Vol. 49, No. June, pp. 4297-4304, 2014.

[9] NAGAJOTHI, S., ELAVENIL, S.: Study of Glass Fibre Reinforced Polymer in Geopolymer Concrete using M-Sand, International Journal of Applied Engineering Research, Vol. 11, pp. 1006-1011, 2016.

[10] VIJAYA RANGAN, B.: Mix Design and Production of Fly Ash Based Geopolymer Concrete, Indian Concrete Journal, Vol. 82, pp. 7-15, 2008.

\section{Review process}

Single-blind peer review process. 